\title{
Antimicrobial Activity of Ephedra pachyclada Methanol Extract on Some Enteric Gram Negative Bacteria Which Causes Nosocomial Infections by Agar Dilution Method
}

\author{
Amin Sadeghi Dosari, ${ }^{1}$ Amin Norouzi, ${ }^{1}$ Majid Taati Moghadam, ${ }^{1,}{ }^{*}$ and Naghmeh Satarzadeh ${ }^{2}$ \\ ${ }^{1}$ Department of Microbiology, Kerman Medical Students Research Committee, Afzalipour Faculty, Kerman University of Medical Sciences, Kerman, Iran \\ ${ }^{2}$ Department of Biotechnology, Students Research Committee, Science Faculty, Tehran Payam Noor of University, Tehran, Iran \\ "Corresponding author: Majid Taati Moghadam, Department of Microbiology, Kerman Medical Students Research Committee, Kerman University of Medical Sciences, Kerman, \\ Iran. E-mail: majidtaati1367@yahoo.com
}

Received 2015 September 06; Revised 2015 October 04; Accepted 2016 October 28.

\begin{abstract}
Background: Past history indicates that plants were served as an important source of medicine. Otherwise, in developing countries people use medicinal plants against infectious disease because they cannot afford expensive drugs. Due to increasing rate of drugresistant diseases, there is an urgent need to detect novel antimicrobial compounds from medicinal plants.

Objectives: The aim of the present study was to determine Antimicrobial activity of Ephedra pachyclada methanol extract on some enteric Gram-negative bacteria which causes nosocomial infections by agar dilution method.

Methods: In this cross-sectional study, in order to examine the antimicrobial effects of Ephedra pachyclada extract on intestinal Gram-negative bacteria, we exposed them to 0/128, 0/25, 0/5,1,2, 4 and $8 \mathrm{mg} / \mathrm{mL}$ of the extract. Ephedra pachyclada was collected from Jiroft Heights and methanolic extract was prepared with maceration method, during which, 50 gr powder of Ephedra pachyclada was dissolved in $300 \mathrm{~mL}$ of $80 \%$ methanol.

Results: In this study, the antibacterial effects of Ephedra pachyclada extract on Gram-negative bacteria such as Pseudomonas aeruginosa, Escherichia coli (PTCC-O157), Escherichia coli (ATCC-25922), Klebsiella pnemoniae, Serratia marcescens was investigated, defining the minimum inhibitory concentration (MIC) by agar dilution method. It has been demonstrated that methanolic extract of Ephedra pachyclada affect intestinal Gram-negative bacteria.

Conclusions: The result showed that, Ephedra pachyclada extract has effective antimicrobial ingredients which are cheap and readily available. It can be used for medicinal purposes in the production of antimicrobial drug.
\end{abstract}

Keywords: Agar Dilution, MIC, Drug-Resistant, Ephedra pachyclada

\section{Introduction}

Enteric Gram-negative bacilli constitute a large group of bacteria which are naturally positioned in intestinal tracts of human and animals. These bacteria include several genera. Some of these bacteria are normal floras which accidentally contribute to disease, while others are always pathogenic to humans [1]. These bacteria are defined as enteric bacteria due to their colonization in intestine or bowel [2].

Past history indicates that plants were served as an important source of medicine. On the other hand, several factors such as incidence of allergies and emergence of antibiotic-resistant strains among bacteria, indicates the importance of medicinal plants [3]. There exist several reports suggesting antimicrobial effects of plant extracts [49].

Increasing price of drugs made researchers to follow plants as important sources of potent drugs. Traditional knowledge have vital role in using medicinal plants as a remedy and discovery of potent drugs to address increasing health problems [10]. Otherwise, in developing countries people use medicinal plants against infectious disease because they cannot afford expensive drugs. Due to increasing rate of drug-resistant diseases, there is an urgent need to detect novel antimicrobial compounds from medicinal plants [11-13]. Ephedra pachyclada plant belongs to the Ephedraceae family and its boiled young branches are used to relieve peptic ulcers and stomachache. Ephedra pachyclada is known as traditional medicine among rural residents and the elderlies [14]. According to numerous conducted studies; phenolic compounds is the active ingredient of this plant.

Researchers also found a direct relation between phenolic compounds of this plant and antioxidant and antimi- 
crobial activity. In Ephedra pachyclada plant; phenolic compounds have a crucial role in inhibitory activity of the hydroxyl groups on free radicals. Therefore, these phenolic compounds may be in direct relation with antioxidant activity of flavonoids and phenylpropanoids biosynthesis [15]. Also, several studies examined antimicrobial effects of Ephedra pachyclada plant on microorganisms. In a study conducted by Bonjar and his colleagues in Iran, antimicrobial effects of Ephedra species which is called Ephedra intermedia were examined [16]. Mahdavi Meymand et al. also examined antimicrobial effects of Ephedra procera [9]. Parsaeimehr et al. examined antimicrobial effects of three species of Ephedra namely E. procera,E. strobiliacea, and E. pachyclada [15]. Azarnia and his colleagues studied protective effects of Ephedra pachyclada on animal models with hepatic disease [17]. Also in other countries, Motomura et al. and Lee et al. also, studied antimicrobial effects of Ephedra pachyclada species $[18,19]$. Iran is a country with a long history in traditional medicine and use of medicinal plants in treatment of diseases. Rich plant flora of Iran and knowledge of Iranian people about medicinal plants, scientific centers in the cities of Isfahan, Shiraz and Ray, scientific resources such as Abo Ali Sina and Razi's books (which promoted use of medicinal plants among Iranian people), and Iranian attention and interest toward medicinal plants demonstrate the importance of medicinal plants in Iran. Note that the use of herbal plants has different customs, traditions, and methods, therefore the adopted methods are different in various locations. According to diversity of climate, Kerman has diverse vegetation and so far different regions such as Bidkhon, Bardsir, Bam, Chatrud and Jiroft have been studied by several researchers [10].

\section{Methods}

In this cross-sectional study, Ephedra pachyclada was collected from Jiroft Heights and then was transported to faculty of biology of Kerman University in order to identify and confirm the genus and species. After confirmation of Ephedra pachyclada; branches and flowers of the plant were dried, crushed, and the powder was used to prepare the extracts.

\subsection{Preparation Plant Extraction}

The methanolic extract was prepared by dissolving 50 gr of the Ephedra pachyclada powder in $300 \mathrm{~mL}$ of $80 \%$ methanol. The powder was mixed with methanol in order to provide uniform extract. Then the extract was kept in the dark for 48 hours After this period, the prepared extract was condensed in the incubation at $40^{\circ} \mathrm{C}$ to be dehydrated.
Maceration method; used in this study; do not impose any damage to the ingredients of the extracts $[3,5]$.

Agar dilution method: Sensitivity of six bacterial species was determined by using agar dilution method in accordance to minimum inhibitory concentration of growth. At first various dilutions of the extracts with the concentrations of $0.128,0.25,0.5,1,2,4$ and $8 \mathrm{mg} / \mathrm{mL}$ were prepared in Mueller Hinton agar media. After that, a suspension equal to 0.5 McFarland concentration was prepared from Pseudomonas aeruginosa, Escherichia coli, Klebsiella pnemoniae, Serratia marcescens. Then inoculation of $10 \mu \mathrm{L}$ of bacterial suspension on Mueller Hinton agar containing various dilutions of the extract was done by using a sampler. The plates were incubated for 24 hours at $37^{\circ} \mathrm{C}$ and then were examined.

\section{Results}

In this study, intestinal Gram-negative bacteria were exposed to $0.128,0.25,0.5,1,2,4$ and $8 \mathrm{mg} / \mathrm{mL}$ of Ephedra pachyclada extract in order to examine its' antimicrobial effects. It was demonstrated that methanolic extract of Ephedra pachyclada affect intestinal Gram-negative bacteria. All bacteria grew at 0.1280 .25 and $0.5 \mathrm{mg} / \mathrm{mL}$ concentrations whereas the minimum inhibitory concentrations (MIC) of methanolic extract on Pseudomonas aeruginosa and other bacteria were observed at 0.5 and $1 \mathrm{mg} / \mathrm{mL}$, respectively. No antimicrobial effects were observed on each of six strains at concentrations of 0.25 and $0.128 \mathrm{mg} / \mathrm{mL}$.

Table 1. The Six Standard Strains

\begin{tabular}{lc}
\hline & Standard Strains \\
\hline Pseudomonas aeruginosa & (ATCC-27853) \\
\hline Klebsiella pneumoniae & (PTCC-1053) \\
\hline Escherichia coli & (PTCC-O157) \\
\hline Escherichia coli & (ATCC-25922) \\
\hline Serratia marcescens & (PTCC-1111) \\
\hline Shigella dysenteriae & (PTCC-1188) \\
\hline
\end{tabular}

\section{Discussion}

Antibiotics are the first line treatment for bacterial infections. Based on findings of the current study, methanolic extracts of Ephedra pachyclada plant (with defining minimum inhibitory concentration (MIC) by agar dilution method) have antibacterial effects on Pseudomonas aeruginosa, Klebsiella pneumoniae, Escherichia coli, Serratia marcescens and Shigella dysenteriae at concentrations of 0.5 
Table 2. The Effect of Ephedra pachyclada Extract on the Six Standard Strains ${ }^{\mathrm{a}}$

\begin{tabular}{|c|c|c|c|c|c|c|c|}
\hline Concentration Bacteria & 0.128 & 0.25 & 0.5 & $\mathbf{1}$ & 2 & 3 & 4 \\
\hline Pseudomonas aeruginosa & + & + & - & - & - & - & - \\
\hline Klebsiella pneumonia & + & + & + & - & - & - & - \\
\hline Escherichia coli (PTCC-0157) & + & + & + & - & - & - & - \\
\hline Escherichia coli (ATCC-25922) & + & + & + & - & - & - & - \\
\hline Serratia marcescens & + & + & + & - & - & - & - \\
\hline Shigella dysentery & + & + & + & _- & _ & _- & _ \\
\hline
\end{tabular}

${ }^{a}$ Note: Sign (-) indicates that the extract is effective while (+) indicates that the extract is not effective at that level of concentration against the bacteria.

, 1, 2, 4 and $8 \mathrm{mg} / \mathrm{mL}$ of. It has been demonstrated that Pseudomonas aeruginosa is the most sensitive bacteria to methanolic extracts of Ephedra pachyclada. However; due to increasing rate of antibiotic-resistant bacteria and side effects of drugs; using a new method to treat these infections is of vital significance. Nowadays, herbal extracts are effective in treatment of bacterial infections and has attracted a lot of attention $[12,20]$. Currently, medicinal plants and their derivatives account for 20 percent and 80 percent of medicinal prescriptions in developed and developing countries, respectively. United States of America is the largest herbal medicine market in the world and Japan is the largest importer of medicinal plants in Asia [21].

In a study conducted by Mahdavi et al. on Pseudomonas aeruginosa, Escherichia coli, Klebsiella pneumoniae and other bacteria; Ephedra pachyclada had an inhibitory effect on these bacteria which is in agreement with the findings of current study [9]. In the past few years, several effects of Ephedra pachyclada extract on different bacteria have been reported. In 2010, Parsaismehr and his colleagues studied antibacterial effects of three species of Ephedra on Gram negative bacteria and unexpectedly observed that the most antimicrobial effect of these plant was on Pseudomonas aeruginosa, which corresponded with the results of the current study [15]. In 2009, Chi-hoon lee and colleagues examined antimicrobial effect of the Ephedra pachyclada plant on some intestinal bacteria, and observed that Ephedra pachyclada has antibacterial effect on some intestinal bacteria at $1 \mathrm{mg} / \mathrm{mL}$ concentration [19]. Finally, some of limitations of current study contain, much data for easy analysis, and the complexity of data is difficult to represent simply.

\subsection{Conclusion}

In this study, sensitivity of several intestinal bacteria to extracts of Ephedra pachyclada was obvious. Hence, the risk of infections induced by these bacteria can be reduced and treatment of these infections can be increased through us- ing Ephedra pachyclada extracts. According to considerable antimicrobial effects of Ephedra pachyclada extracts on Gram-negative bacteria (especially Pseudomonas), wide spectrum of diseases caused by these bacteria, and increasing rates of antibiotic resistance; effective ingredients of Ephedra pachyclada can be extracted in order to prevent the prevalence of these bacteria in communities and hospitals and treatment of infections.

According to the current study and assessments of Ephedra Pachyclada effects, it is recommended to develop investigations on synergistic effects of this plant with drugs effective on Pseudomonas and other pathogenic Gram-negative bacteria. Finally, it is recommended to use Ephedra pachyclada extract in producing new antibiotics.

\section{Acknowledgments}

The authors kindly thank of Kerman Medical students research committee for financially supporting this work (Code 93/500).

\section{Footnotes}

Authors' Contribution: All authors had equal role in design, work, statistical analysis.

Funding/Support: Kerman University of Medical Sciences.

\section{References}

1. Jawetz M. elnick, and Adelberg's. Medical microbiology. 25 ed. New York: McGraw Hill; 2010.

2. aqvi K, Joniedi Jafari N, Karami A. Molecular analysis of nalidixic acid resistance in E. coli Isolated from Patients with Urinary Tract Infection Hospital Baghiatallah [ in Persian ]. J Mil Med. 2006;8(3):191-6.

3. Salehi M, Raisnia N, Mehrabian S. Evaluate the antibacterial effect of methanol extract of outer shell pistachio vera [in Persian].J M Biothecnology. 2012;10:53-9. 
4. Poor zahir T, Zandi H, Botorabi Z. Comparison of the effects of licorice boiled with selected antibiotics on Helicobacter pylori growth in vitro [ in Persian ]. J Shahid Sadoughi Univ Med Sci. 2006;13(3):45-52.

5. Jalali M, Abedi D, Ghasemi D, Chaharmahali A. Evaluation of antibacterial activity of ethanol extracts of some medicinal plants against Listeria monocytogenes [in Persian]. J Shahrekord Univ Med Sci. 2007;8:25-33.

6. Dakhili M. Evaluation of Antimicrobial effects of four herbal essences on Salmonella typhi Murium and comparison with current antibiotics in veterinary [in Persian]. Herbs Q. 2006;20:21-7.

7. Kazem Alvandi R, Sharifian A, Aghazadeh Meshgi M. Study of chemical composition and antimicrobial activity of peppermint essential oil [in Persian]. J Comp Pathobio Ir. 2011;4:355-64.

8. Moosavian M,Siahpoosh A, Abbasi E, Darabifar H. The effects of hydroethanolic Albizzia lebbeck extract on enteric gram-negative and aerobic gram-positive bacilli [in Persian]. Arak Med Univ J. 2010;15(13 (1)):119-26.

9. Mahdavi Meymand Z, Moshafi MH, Forotanfar H. Antimicrobial Effects of methanol extracts of 12 Herbal species on 6 bacterial strains using cylinder-plate [in Persian]. J Rafsanjan Univ Med Sci. 2010;3:22737.

10. Balangcod TD, Vallejo VL, Patacsil M, Apostol O, Laruan LMVA, Manuel J. Phytochemical screening and Antibacterial activity of selected medicinal plants of Bayabas, Sablan, Benguet Province, Cordillera Administrative Region, Luzon, Philippines. Ind J Tra Knowledge. 2012;11(4):580-5.

11. Gutierrez RM, Baculi R, Pastor N, Puma-at T, Balangcod T. Antibacterial potential of some medicinal plants of the Cordillera Region, Philippines. Ind J Tra Knowledge. 2013;12(4):630-7.

12. Mozaffari Nejad AS, Kamkar A, Giri A, Pourmahmoudi AA. Ethnobotany and folk medicinal uses of Major Trees and Shrubs in Northern
Iran.J Med Plants Res. 2013;7:284-9. doi: 10.5897/JMPR11.680.

13. Jalali H, Mozaffari Nejad AS, Ebadi AG, Laey G. Ethnobotany and Folk Pharmaceutical Properties of Major Trees or Shrubs in Northeast of Iran. Asian J Chem. 2009;21(7):5632-8.

14. Sharififar F, Koohpayeh A, Amir Khosravi A. Evaluation ethanolic Medicinal Plants of Sirjan, Kerman [ in Persian]. J Herbal Drugs. 2010;9(36):19-28.

15. Parsaeimehr A, Sargsyan E, Javidnia K. A comparative study of the antibacterial, antifungal and antioxidant activity and total content of phenolic compounds of cell cultures and wild plants of three endemic species of Ephedra. Molecules. 2010;15(3):1668-78. doi: 10.3390/molecules15031668. [PubMed: 20336006].

16. Shahidi Bonjar GH. Evaluation of Antibacterial Properties of Iranian Medicinal-Plants against Micrococcus luteus, Serratia marcescens, Klebsiella pneumoniae and Bordetella bronchoseptica. Asian J Plant Sci. 2004;3(1):82-6. doi: 10.3923/ajps.2004.82.86.

17. Azarnia M, Ghasemi M. Protective Effects of Ephedra pachyclada on Animal Models with Acute Liver Disease Induced by Carbon Tetrachloride [in Persian]. J Cell Tissue. 2013;3(4):351-62.

18. Motomura H, Noshiro S, Mikage M. Variable wood formation and adaptation to the alpine environment of Ephedra pachyclada (Gnetales: Ephedraceae) in the Mustang district, western Nepal. Ann Bot. 2007;100(2):315-24. doi: 10.1093/aob/mcm111. [PubMed: 17576659].

19. Lee $\mathrm{CH}$, Lee HS. Growth inhibiting activity of quinaldic acid isolated from Ephedra pachyclada against intestinal bacteria.J Korean Society App Bio Chem. 2009;52(4):331-5.

20. Khalaji N, Neyestani T. The inhibitory effects of black and green teas (Camellia sinensis) on growth of pathogenic Escherichia coli in vitro. J Nut Sci Food Technol. ;1(3):33-8.

21. Hans F. Medicinal plants. 3 ed. Tehran: behan Publisher; 1990. 